\title{
A Multicenter Study of Tongue Lesions from Thailand
}

\author{
Kittipong Dhanuthai ${ }^{1}$ Sompid Kintarak ${ }^{2} \quad$ Ajiravudh Subarnbhesaj ${ }^{3} \quad$ Nutchapon Chamusri $^{4}$
}

${ }^{1}$ Department of Oral Pathology, Faculty of Dentistry, Chulalongkorn University, Bangkok, Thailand

${ }^{2}$ Department of Stomatology, Faculty of Dentistry,

Prince of Songkla University, Hatyai, Songkhla, Thailand

${ }^{3}$ Department of Oral Diagnosis, Faculty of Dentistry,

Khon Kaen University, Khon Kaen, Thailand

${ }^{4}$ Department of Oral Biology and Oral Diagnostic Sciences,

Faculty of Dentistry, Chiang Mai University, Chiang Mai, Thailand

\author{
Address for correspondence Kittipong Dhanuthai, DDS, MSC, \\ Department of Oral Pathology, Faculty of Dentistry, Chulalongkorn \\ University, Pathum Wan District, Bangkok 10330, Thailand \\ (e-mail: fibroma123@yahoo.com).
}

Eur J Dent:2020;14:435-439

\begin{abstract}
Keywords

- demographic and pathologic features

- prevalence

- Thailand

- tongue lesions

Objective Tongue lesions constitute a considerable proportion of the oral lesions. Previous studies on tongue lesions were based on clinical studies. There has been a scarcity of the studies which are based on histopathological examination. This study aimed to determine the prevalence, demographic, and pathologic features of tongue lesions from Thailand.

Materials and Methods Biopsy records of the participating institutions were reviewed for lesions on the tongue diagnosed during 1998 to 2017. Demographic data were collected from the biopsy records. Locations were arbitrarily classified as dorsal, lateral, and ventral surfaces, tip of the tongue, and the combination of sites. Lesions of the tongue were classified as reactive/inflammatory, developmental, immune-mediated, cystic, benign, premalignant, malignant, infectious, and miscellaneous categories.

Statistical Analysis Data were analyzed by descriptive statistics using SPSS version 20.0. Results Of the 44,188 accessioned cases, 2,153 cases (4.87\%) were diagnosed from the tongue. The age of the patients ranged from 3 to 93 years with the mean \pm standard deviation $=45.26 \pm 20.48$ years. The female-to-male ratio was 1.49:1. The majority of the tongue lesions were encountered at the lateral border of the tongue (47.66\%). Most of the tongue lesions in the present study (53.74\%) fell into the reactive/inflammatory category. Irritation fibroma was the most prevalent lesion (18.99\%) followed by squamous cell carcinoma (16.91\%), and mucus extravasation phenomenon (14.26\%), respectively.

Conclusions This study offers new perspective into the study of tongue lesions apart from the clinically based studies. It also demonstrates the difference between the pediatric and the elderly patients. This study provides invaluable database for clinicians when formulating the clinical diagnosis of tongue lesions.
\end{abstract}

\section{Introduction}

Tongue is a muscular organ which serves numerous important functions such as phonation, deglutition, perception of sensations, such as, taste, thermal changes, pain and general sensations, and also has a role in the development of the jaws. ${ }^{1,2}$ Tongue consists principally of skeletal muscle, but it also harbors blood vessels, nerves, fat cells, minor salivary glands, and lymphoid tissues, all of which can give rise to both neoplastic and non-neoplastic lesions. Due to the easily accessible locale in the oral cavity, examination of the tongue can give valuable diagnostic information since both local as well as systemic diseases or syndromes can have manifestations in the tongue. ${ }^{3,4}$ 
There have been several epidemiological studies on oral mucosal lesions and tongue lesions constitute a considerable proportion of the oral lesions, ${ }^{5-13}$ but information specific to the tongue lesions is difficult or impossible to extract from those studies. Prevalence of tongue lesions varies in different parts of the world due to demographic and/or geographic differences of the sample studied, as well as differences in the diagnostic criteria, study methodology, and sampling process ${ }^{14}$; hence conducting studies on the prevalence of tongue lesions in different geographic regions seems imperative. Pediatric and geriatric patients are special groups of general population which elicit distinctive oral mucosal lesions, ${ }^{7-13,15}$ so it is interesting to know whether tongue as a subsite of the oral mucosa does the same thing. Most of the previous studies were based on clinical observations without histopathological examination..$^{16-21}$ There has been a scarcity of the studies on tongue lesions which are based on histopathological examination, especially from Thailand. Only two such studies have been documented in the English language literature. ${ }^{22,23}$ The aims of this study were to determine the prevalence and the demographic and pathologic features of tongue lesions from Thailand based on histopathological examination and to compare these findings with studies from other parts of the world.

\section{Materials and Methods}

Biopsy records of the Department of Oral Pathology, Chulalongkorn University, Department of Oral Diagnosis, Khon Kaen University, Department of Oral Biology and Oral Diagnostic Sciences, Chiang Mai University, and Department of Stomatology, Prince of Songkla University were reviewed for lesions on the tongue diagnosed during 1998 to 2017.

\section{Inclusion Criteria}

The inclusion criteria were all biopsy cases from the tongue diagnosed during the aforementioned period.

\section{Exclusion Criteria}

The exclusion criteria consisted of the following conditions:

- All biopsy cases not diagnosed during the aforementioned period.

- All biopsy cases from locations other than the tongue.

- Biopsy cases from the tongue with the diagnosis of normal tissue or inadequate specimen.

Demographic data were collected from the biopsy records. Age of the patients was subdivided into 10-year intervals. Location of lesions on the tongue was arbitrarily classified as dorsal, lateral, and ventral surfaces, tip of the tongue as well as the combination of sites. Lesions of the tongue were classified as reactive/inflammatory, developmental, immune-mediated, cystic, benign, premalignant, malignant, infectious, and miscellaneous categories. Data were analyzed by descriptive statistics using SPSS version 20.0 (SPSS Inc.; Chicago, Illinois, United States). This research was approved by The Human Research Ethics Committee of the Faculty of Dentistry, Chulalongkorn University (No.092/2018).

\section{Results}

Of the 44,188 accessioned cases, 2,153 cases (4.87\%) were diagnosed from the tongue. The prevalence ranged from $4.01 \%$ from Prince of Songkla University in the South of Thailand to 6.06\% from Khon Kaen University in the Northeast of Thailand. The age of the patients ranged from 3 to 93 years with the mean \pm standard deviation $(S D)=45.26 \pm 20.48$ years

(-Table 1). The majority of the patients fell in the fifth to the seventh decades of life. Two hundred and ninety-five cases (13.70\%) were discovered in children aged 16 and below. Three hundred and sixty-five cases (16.95\%) were found in the elderly (aged 65 and above). Mean age of the pediatric patients \pm SD was $10.48 \pm 3.46$, while that of the elderly patients was $72.32 \pm 6.02$ years.

Regarding gender, 1,285 patients (59.68\%) with tongue lesions were females, while 865 patients (40.18\%) with

Table 1 Age, gender, and location of tongue lesions according to histopathological categories

\begin{tabular}{|c|c|c|c|c|}
\hline Histopathological category & Number (\%) & Age (Mean $\pm S D)$ & Gender (M:F) & Most common location (\%) \\
\hline Reactive/inflammatory lesions & $1,158(53.76 \%)$ & $39.53 \pm 21.70$ & $452: 705$ & Lateral border (37.56\%) \\
\hline Malignant tumors & $380(17.61 \%)$ & $56.09 \pm 14.47$ & 199:180 & Lateral border (73.16\%) \\
\hline Premalignant lesions & $183(8.50 \%)$ & $54.55 \pm 14.47$ & 77:106 & Lateral border (79.23\%) \\
\hline Benign tumors & $179(8.31 \%)$ & $47.33 \pm 17.55$ & $73: 105$ & Lateral border (37.43\%) \\
\hline Immune-mediated lesions & $87(4.04 \%)$ & $49.45 \pm 13.57$ & 19:68 & Lateral border (55.17\%) \\
\hline Developmental lesions & $79(3.67 \%)$ & $38.73 \pm 20.58$ & $20: 59$ & Dorsal surface $(63.29 \%)$ \\
\hline Infection & $59(2.74 \%)$ & $50.09 \pm 18.82$ & 20:39 & Dorsal surface (42.37\%) \\
\hline Cysts & $7(0.33 \%)$ & $46.40 \pm 15.99$ & $2: 5$ & $\begin{array}{l}\text { Lateral border }(42.86 \%) \text { and } \\
\text { ventral surface }(42.86 \%)\end{array}$ \\
\hline Miscellaneous & $21(0.96 \%)$ & $58.14 \pm 16.46$ & $3: 18$ & Lateral border (52.38\%) \\
\hline Total & $2,153(100 \%)$ & $45.26 \pm 20.48$ & $865: 1,285$ & Lateral border (47.38\%) \\
\hline
\end{tabular}

Abbreviation: SD, standard deviation. 
tongue lesions were males. The female-to-male ratio was 1.49:1 ( Table 1). All participating institutions demonstrated a higher number of female patients than male patients. Both the pediatric and the elderly groups also elicited a female predilection. Some lesions elicited a female predilection such as lichen planus/lichenoid reaction (75.0\%), papilloma (64.62\%), mucus extravasation phenomenon (mucocele, 63.19\%), irritation fibroma (focal fibrous hyperplasia, 62.01\%), and epithelial dysplasia (58.58\%), while squamous cell carcinoma demonstrated a slight male predilection (52.75\%).

The majority of the tongue lesions were encountered at the lateral border of the tongue (47.38\%) followed by dorsal surface of the tongue (21.37\%), ventral surface of the tongue (20.67\%), and tip of the tongue (7.76\%), respectively (-Table 1). The rest were accounted for by the combination of sites and the missing data. It was noteworthy that some lesions had preferential anatomical locations. For example, $88.93 \%$ of mucus extravasation phenomena (mucocele) were encountered at the ventral surface of the tongue. Lateral border of the tongue was the predilection site for squamous cell carcinoma (73.90\%) and epithelial dysplasia (79.29\%). Lichen planus/lichenoid reaction was frequently found at lateral border of the tongue (52.78\%) followed by dorsal surface of the tongue (40.28\%).

Most of the tongue lesions in the present study (53.79\%) fell into the reactive/inflammatory category followed by malignant tumor category (17.65\%), benign tumor category (8.31\%), premalignant category (8.50\%), immune-mediated category (4.04\%), developmental category (3.67\%), infectious category $(2.74 \%)$, miscellaneous $(0.98 \%)$, and cystic category (0.33\%), respectively (-Table 2 ). Irritation fibroma (focal fibrous hyperplasia) was the most prevalent lesion (19.04\%) followed by squamous cell carcinoma (16.91\%) and mucus extravasation phenomenon (mucocele, 14.26\%), respectively. Within the reactive/inflammatory category, irritation fibroma (focal fibrous hyperplasia) was the most common lesion in this category (19.04\% of all the cases and $35.41 \%$ of the reactive/inflammatory category), followed by mucus extravasation phenomenon (mucocele, $14.26 \%$ of all the cases and $26.51 \%$ of the reactive/inflammatory category) and pyogenic granuloma ( $4.83 \%$ of all the cases and $8.98 \%$ of the reactive/inflammatory category), respectively.

In the pediatric patients, the most common tongue lesion was mucus extravasation phenomenon (mucocele, $70.17 \%$ of the pediatric patients), followed by irritation fibroma (focal fibrous hyperplasia, $7.46 \%$ of the pediatric patients), and pyogenic granuloma (5.42\% of the pediatric patients), respectively. In the elderly patients, the most common tongue lesion was squamous cell carcinoma (28.77\% of the elderly patients), followed by irritation fibroma (focal fibrous hyperplasia, $13.42 \%$ of the elderly patients), and epithelial dysplasia (9.59\% of the elderly patients), respectively.

\section{Discussion}

To the best of our knowledge, this is the first study to determine the prevalence, demographic, and pathologic features of tongue lesions from virtually all corners of Thailand.
Table 2 Histopathological diagnosis of tongue lesions

\begin{tabular}{|c|c|}
\hline Histopathological diagnosis & Number \\
\hline Reactive/inflammatory lesions & 1,158 \\
\hline $\begin{array}{l}\text { Irritation fibroma (focal fibrous } \\
\text { hyperplasia) }\end{array}$ & 410 \\
\hline $\begin{array}{l}\text { Mucus extravasation phenomenon } \\
\text { (mucocele) }\end{array}$ & 307 \\
\hline Pyogenic granuloma & 104 \\
\hline Nonspecific ulcer & 88 \\
\hline Hyperkeratosis/hyperparakeratosis & 65 \\
\hline Chronic inflammation & 54 \\
\hline $\begin{array}{l}\text { Traumatic ulcerative granuloma with } \\
\text { stromal eosinophilia }\end{array}$ & 48 \\
\hline Others & 82 \\
\hline Malignant tumors & 380 \\
\hline Squamous cell carcinoma & 364 \\
\hline Verrucous carcinoma & 10 \\
\hline Kaposi’s sarcoma & 2 \\
\hline Others & 4 \\
\hline Benign tumors & 179 \\
\hline Papilloma & 130 \\
\hline Lipoma & 18 \\
\hline Neurilemmoma & 12 \\
\hline Granular cell tumor & 6 \\
\hline Others & 13 \\
\hline Premalignant lesions & 183 \\
\hline Epithelial dysplasia & 169 \\
\hline Carcinoma in situ & 14 \\
\hline Immune-mediated lesions & 87 \\
\hline Lichen planus/lichenoid reaction & 76 \\
\hline Lupus erythematosus & 4 \\
\hline Pemphigus vulgaris & 3 \\
\hline Others & 4 \\
\hline Developmental lesions & 79 \\
\hline Vascular malformation & 60 \\
\hline Choristoma & 9 \\
\hline Harmatoma & 3 \\
\hline Others & 7 \\
\hline Infection & 59 \\
\hline Candidiasis & 28 \\
\hline Verruca vulgaris & 11 \\
\hline Histoplasmosis & 5 \\
\hline Others & 15 \\
\hline Cysts & 7 \\
\hline Miscellaneous & 21 \\
\hline
\end{tabular}

Previous study from Thailand by Jainkittivong and Langlais focused exclusively on geographic tongue. ${ }^{22}$ Tongue lesions in the present study constituted $4.87 \%$ of all biopsy cases from 
Thailand which is comparable to $3.51 \%$ by Shamloo et al, ${ }^{24}$ $4.00 \%$ by Lasisi and Abimbola, ${ }^{25}$ and $6.30 \%$ by Alaeddini et al, ${ }^{2}$ but lower than most of the clinical studies such as $9.20 \%$ by Byahatti and Ingafou, ${ }^{19} 18.52 \%$ by Bánóczy et al, ${ }^{17} 23.70 \%$ by Darwazeh and Pillai, ${ }^{5} 30.20 \%$ by Koay et al, ${ }^{20} 35.11 \%$ by Vörös-Balog et al, ${ }^{18} 52.23 \%$ by Avcu and Kanli, ${ }^{14}$ and $76.50 \%$ by Al-Wesabi et al. ${ }^{16}$ Most of the clinical studies ${ }^{5,16-21}$ revealed that either geographic tongue or fissured tongue was the most common tongue lesion, while the biopsy-based studies ${ }^{24-27}$ showed that either irritation fibroma or squamous cell carcinoma was the most prevalent tongue lesion except the study by Alaeddini et $\mathrm{al}^{2}{ }^{2}$ which demonstrated that lichen planus was the most common tongue lesion followed by irritation fibroma and squamous cell carcinoma, respectively. In fact, the prevalence of tongue lesions should be higher than in the present study since lesions such as geographic tongue, ankyloglossia, or fissured tongue are usually diagnosed in the clinic, and are not submitted for histopathological examination. Both the studies based on clinical data and the ones from biopsy records have advantages and disadvantages. Clinical studies can recruit a larger number of samples, but the drawback of this type of study is the accuracy of the diagnosis, for example, a clinical diagnosis of squamous cell carcinoma can only be confirmed by biopsy and histopathological examination. Moreover, entities such as epithelial dysplasia, carcinoma in situ, or submucosal lesions never appear in the clinical studies. Biopsy-based studies have the advantage of being accurate, as biopsy is regarded as the gold standard in the diagnosis. As a consequence, data collected, which are invariably smaller than the clinical studies unless collaborative multicenter study like the present one is performed, might not be a good representative of the population studied as in the clinical studies.

The mean age of the patients in the present study was 45.26 years which is in accordance with most previous studies based on histopathological examination; 44.50 years by Miyake et al, ${ }^{28} 45.30$ years by Costa et al, ${ }^{26} 46.41$ years by Lasisi and Abimbola, ${ }^{25} 47.00$ years by Alaeddini et al, ${ }^{2}$ 48.00 years by Shamloo et al, ${ }^{24}$ but higher than 24.00 years by Al-Wesabi et al, ${ }^{16} 33.00$ years by Byahatti and Ingafou, ${ }^{19}$ 36.51 years by Mushatat et al, ${ }^{21}$ or in the 6 to 10 -year-aged group by Vörös-Balog et al. ${ }^{18}$ The study by Vörös-Balog et al ${ }^{18}$ focused on tongue lesions in Hungarian children. The studies by Al-Wesabi et $\mathrm{al}^{16}$ and by Byahatti and Ingafou ${ }^{19}$ used median age instead of mean age.

The distribution of tongue lesions between both genders varied. Some previous studies ${ }^{17,19-21,24,28}$ including the present study as well as the large-scaled biopsy-based study by Alaeddini et $\mathrm{al}^{2}$ demonstrated the female predominance, while others revealed the opposite. ${ }^{5,14,16,18,25-27,29}$ The reason why tongue lesions were encountered in men more than in women in a large-scaled clinical study from Turkey is accounted for by the fact that smoking, black tea drinking, and poor oral hygiene are more prevalent in men than in women. ${ }^{14}$

In the present study, lateral border of the tongue was the most common site which is in accordance with the studies by Aittiwarapoj et al, ${ }^{23}$ Shamloo et al, ${ }^{24}$ Gambino et al, ${ }^{27}$ and Miyake et $\mathrm{al}^{28}$. Ion Ciucă Mărăşescu et $\mathrm{al}^{29}$ reported that two-thirds of carcinoma of the tongue developed in the mobile part of the tongue, especially the margins. This may be attributed to the fact that irritation fibroma (focal fibrous hyperplasia) and squamous cell carcinoma are preferentially encountered at the lateral border of the tongue. ${ }^{30,31}$ However, the studies by Lasisi and Abimbola ${ }^{25}$ and Alaeddini et $\mathrm{al}^{2}$ revealed that dorsum of the tongue was the most common site. Although the study by Alaeddini et $\mathrm{al}^{2}$ ranked dorsum of the tongue as the most predilection site (45.8\%), lateral surface of the tongue came in the second rank (40.6\%). Some entities had the predilection for certain sites on the tongue. For example, mucus extravasation phenomenon (mucocele) preferentially occurred at the ventral surface of the tongue, squamous cell carcinoma and epithelial dysplasia at the lateral border of the tongue, and lichen planus/lichenoid reaction at lateral border of the tongue followed by dorsal surface of the tongue, respectively.

Most of the clinical studies ${ }^{5,16-21}$ revealed that fissured tongue was the most common tongue lesion. However, the study by Avcu and Kanli ${ }^{14}$ found that coated tongue was the most prevalent tongue lesion followed by fissured tongue. The present study showed that reactive/inflammatory category was the most frequent category of tongue lesions and irritation fibroma (focal fibrous hyperplasia) was the most common lesion in this category which is in accordance with the studies by Costa et al, ${ }^{26}$ Gambino et $a l,{ }^{27}$ and Miyake et al. ${ }^{28}$ However, the study by Alaeddini et $\mathrm{al}^{2}$ revealed that the immune-mediated category was the most frequent category of tongue lesions followed by the reactive/ inflammatory category. The most common tongue lesion in their study was lichen planus followed by and irritation fibroma (focal fibrous hyperplasia) and squamous cell carcinoma, respectively, while the studies by Shamloo et $\mathrm{al}^{24}$ and Lasisi and Abimbola ${ }^{25}$ showed that squamous cell carcinoma was the most common tongue lesion.

In the pediatric patients, the most common tongue lesion in the present study was mucus extravasation phenomenon (mucocele) which is in accordance with previous studies on pediatric oral lesions based on histopathological examination. ${ }^{7-9,15}$ In the elderly patients, the most common tongue lesion in the present was squamous cell carcinoma which is in accordance with previous studies on geriatric oral lesions based on histopathological examination. ${ }^{10-13}$

\section{Conclusions}

This study offered new perspective into the study of tongue lesions apart from the clinically based studies. Most of the tongue lesions in this study are in the reactive/inflammatory category and irritation fibroma (focal fibrous hyperplasia) is the most common tongue lesion. This study also demonstrated the difference between the pediatric and the elderly patients. Clinicians should thoroughly examine the patient's mouth, paying attention to not only teeth and gum, as other structures such as the tongue may reflect signs of oral 
manifestations of systemic diseases or early stage of malignancy. Early detection and institution of prompt treatment can be life saving for the patients.

\section{Conflict of Interest}

None declared.

\section{Acknowledgment}

The authors would like to thank all the staffs of the participating institutions for their contribution in this research.

\section{References}

1 du Toit DF. The tongue: structure and function relevant to disease and oral health. SADJ 2003;58(9):375-376, 380-383

2 Alaeddini M, Barghammadi R, Eshghyar N, Etemad-Moghadam S. An analysis of biopsy-proven tongue lesions among 8,105 dental outpatients. J Contemp Dent Pract 2014;15(1):1-7

3 Nagaraj V, Sashykumar S, Viswanathan S, Kumar S. Multiple oral ulcers leading to diagnosis of pulmonary tuberculosis. Eur J Dent 2013;7(2):243-245

4 Suvirya S, Gandhi R, Agarwal J, Patil R. Erythematous candidiasis leading to systemic manifestations of human immunodeficiency virus co-infection with secondary syphilis: a diagnostic and therapeutic dilemma. Eur J Dent 2015;9(3):449-452

5 Darwazeh AM, Pillai K. Prevalence of tongue lesions in 1013 Jordanian dental outpatients. Community Dent Oral Epidemiol 1993;21(5):323-324

6 Lin HC, Corbet EF, Lo EC. Oral mucosal lesions in adult Chinese. J Dent Res 2001;80(5):1486-1490

7 Hong CHL, Dean DR, Hull K, et al. World Workshop on Oral Medicine VII: relative frequency of oral mucosal lesions in children, a scoping review. Oral Dis 2019;25(suppl 1) :193-203

8 Silva LVO, Arruda JAA, Martelli SJ, et al. A multicenter study of biopsied oral and maxillofacial lesions in a Brazilian pediatric population. Braz Oral Res 2018;32:e20-e28

9 Cavalcante RB, Turatti E, Daniel AP. de Alencar GF, Chen Z. Retrospective review of oral and maxillofacial pathology in a Brazilian paediatric population. Eur Arch Paediatr Dent 2016;17(2):115-122

10 Dhanuthai K, Rojanawatsirivej S, Somkotra T, et al. Geriatric oral lesions: a multicentric study. Geriatr Gerontol Int 2016;16(2):237-243

11 Qannam A, Bello IO. The range of diagnoses for oral soft-tissue biopsies of geriatric patients in a Saudi Arabian teaching hospital. Saudi Dent J 2016;28(2):96-101

12 Mohan BC, Angadi PV, Hallikerimath S, Kale AD. Diagnoses of 964 oral biopsies from people aged over 50 years in Karnataka State, India. Gerodontology 2016;33(2):217-224

13 Lei F, Chen JY, Wang WC, et al. Retrospective study of oral and maxillofacial lesions in older Taiwanese patients. Gerodontology 2015;32(4):281-287
14 Avcu N, Kanli A. The prevalence of tongue lesions in 5150 Turkish dental outpatients. Oral Dis 2003;9(4):188-195

15 Martins-Filho PR, de Santana Santos T, Piva MR, et al. A multicenter retrospective cohort study on pediatric oral lesions. J Dent Child (Chic) 2015;82(2):84-90

16 Al-Wesabi MA, Al-Hajri M, Shamala A, Al-Sanaani S. Tongue lesions and anomalies in a sample of Yemeni dental patients: a cross-sectional study. J Oral Res 2017;6:121-126

17 Bánóczy J, Rigó O, Albrecht M. Prevalence study of tongue lesions in a Hungarian population. Community Dent Oral Epidemiol 1993;21(4):224-226

18 Vörös-Balog T, Vincze N, Bánóczy J. Prevalence of tongue lesions in Hungarian children. Oral Dis 2003;9(2):84-87

19 Byahatti SM, Ingafou MSH. The prevalence of tongue lesions in Libyan adult patients. J Clin Exp Dent 2010;2:e163-e168

20 Koay CL, Lim JA, Siar CH. The prevalence of tongue lesions in Malaysian dental outpatients from the Klang Valley area. Oral Dis 2011;17(2):210-216

21 Mushatat SF, Salih MF, Othman AA. Prevalence of common nonmalignant tongue lesions. Int J Res Pharm Sci 2017;8:804-808

22 Jainkittivong A, Langlais RP. Geographic tongue: clinical characteristics of 188 cases. J Contemp Dent Pract 2005;6(1):123-135

23 Aittiwarapoj A, Juengsomjit R, Kitkumthorn N, Lapthanasupkul P. Oral potentially malignant disorders and squamous cell carcinoma at the tongue: clinicopathological analysis in a Thai population. Eur J Dent 2019;13(3):376-382

24 Shamloo N, Motazedian HR, Lotfi A. Study on prevalence of pathologic tongue lesions in patients of Tehran capital city of Iran, during a twenty years period. Int J Oral Health Dent 2016;2:217-219

25 Lasisi TJ, Abimbola TA. Clinico-pathologic review of biopsied tongue lesions in a Nigerian tertiary hospital. Ann Ib Postgrad Med 2017;15(2):109-113

26 Costa FW, Osterne RL, Mota MR, Alves AP, Soares EC, Sousa FB. Tongue lesions. J Craniofac Surg 2012;23(6):e548-e551

27 Gambino A, Carbone M, Arduino PG, et al. Clinical features and histological description of tongue lesions in a large Northern Italian population. Med Oral Patol Oral Cir Bucal 2015;20(5):e560-e565

28 Miyake Y, Shinozuka K, Ueki K, et al. Retrospective clinical study of 296 patients with mass lesions of the tongue. J Oral Sci 2018;60(4):574-578

29 Ion Ciucă Mărăşescu FI, Marasescu PC, Matei M, et al. Epidemiological and histopathological aspects of tongue squamous cell carcinomas-retrospective study. Curr Health Sci J 2018;44(3):211-224

30 García-Kass AI, Herrero-Sánchez A, Esparza-Gómez G. Oral tongue cancer in public hospitals in Madrid, Spain (19902008) Med Oral Patol Oral Cir Bucal 2016;21(6):e658-e664

31 Ryu MH, Kim BL, Kim HS, Kim J. Expression of TGF-B1, MMP-1 and TIMP-1 in irritation fibroma. Kor J Oral Maxillofac Pathol 2009;33:61-68 